\title{
Cytoreductive Nephrectomy After Combination of Nivolumab Plus Ipilimumab for Mucinous Tubular and Spindle Cell Carcinoma of the Kidney With Bone Metastases: A Case Report
}

\author{
NOBUKI FURUBAYASHI ${ }^{1}$, KENICHI TAGUCHI ${ }^{2}$, TAKAHITO NEGISHI ${ }^{1}$, AKIHIRO MIURA $^{1}$, \\ YOSHINORI SATO ${ }^{1}$, MAKOTO MIYOSHI $^{1}$ and MOTONOBU NAKAMURA ${ }^{1}$ \\ ${ }^{1}$ Department of Urology, National Hospital Organization Kyushu Cancer Center, Fukuoka, Japan; \\ ${ }^{2}$ Department of Pathology, National Hospital Organization Kyushu Cancer Center, Fukuoka, Japan
}

\begin{abstract}
Background/Aim: Mucinous tubular and spindle cell carcinoma (MTSCC) is a rare subtype of renal cell carcinoma and generally considered a low-grade renal epithelial neoplasm. However, MTSCC with distant metastases often shows a poor prognosis. This is the first reported case of cytoreductive nephrectomy after nivolumab plus ipilimumab combination treatment. Case Report: A 26year-old man had a 72-mm tumor at the left kidney with multiple osteolytic bone metastases. A biopsy of the renal tumor and bone metastases resulted in the diagnosis of MTSCC of the kidney with bone metastases. After nivolumab plus ipilimumab combined treatment, he underwent cytoreductive nephrectomy. The excised specimen showed higher PD-L1 expression in the spindle components than in the tubular components, but CD4- and CD8-positve T-cells showed greater infiltration in the tubular components than the spindle components. Conclusion: Combination immunotherapy of nivolumab and ipilimumab may be an effective treatment option for metastatic MTSCC of the kidney.
\end{abstract}

Mucinous tubular and spindle cell carcinoma (MTSCC) is a rare subtype of renal cell carcinoma (RCC) first defined in the 2004 edition of the World Health Organization Classification (1), and generally considered a low-grade renal epithelial neoplasm composed of tubules, spindle cells, and

This article is freely accessible online.

Correspondence to: Nobuki Furubayashi, Department of Urology, National Hospital Organization Kyushu Cancer Center, Notame 31-1, Minami-ku, Fukuoka 811-1395, Japan. Tel: +81 925413231, Fax: +81 925514585, e-mail: nobumduro@gmail.com

Key Words: Mucinous tubular and spindle cell carcinoma, nivolumab, ipilimumab, bone metastases. extracellular mucin. Fewer than 100 total cases have been reported in the literature (2); however, with the increasing recognition of MTSCC of the kidney, more cases of MTSCC with distant metastases are being reported, some of which have a poor prognosis $(3,4)$. Only case reports have been reported regarding the treatment of metastatic MTSCC, with some targeted agents and monotherapy with immune checkpoint inhibitors having shown some efficacy (3-8).

Only one case report regarding the combination of nivolumab plus ipilimumab for metastatic MTSCC after cytoreductive nephrectomy has been reported, showing some efficacy (9). To our knowledge, however, this is the first reported case of cytoreductive nephrectomy after combination of nivolumab plus ipilimumab for MTSCC of the kidney with bone metastases.

\section{Case Report}

Written informed consent was obtained from the patient for the publication of this case report and any accompanying images.

Clinical history. This patient was a 26-year-old man with a 1-month history of intermittent back pain. He went to a hospital because he had asymptomatic gross hematuria. In our hospital a left renal tumor 72-mm was detected using echography and computed tomography (CT). The tumor was present at the upper pole of the left kidney, wellcircumscribed, slightly enhanced heterogeneously in the corticomedullary phase and excretory phase but without any strong enhancement in the corticomedullary, as is usually observed in clear cell RCC. In addition, multiple osteolytic changes were confirmed in the bone (Figure 1).

A CT-guided biopsy was performed on the left renal tumor, and osteoplastic changes of the second lumbar spine were noted. The left kidney tumor biopsy specimen showed bland tubular structures with focal clear cells, oncocytic changes, and cytoplasmic vacuolation, accompanied by 
A

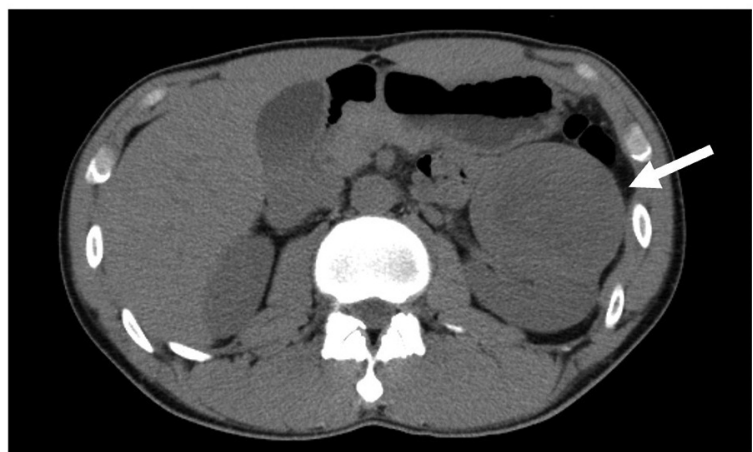

B

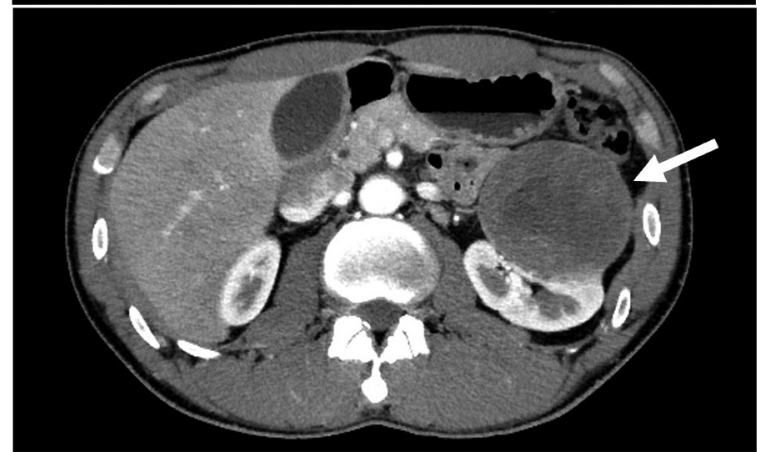

C

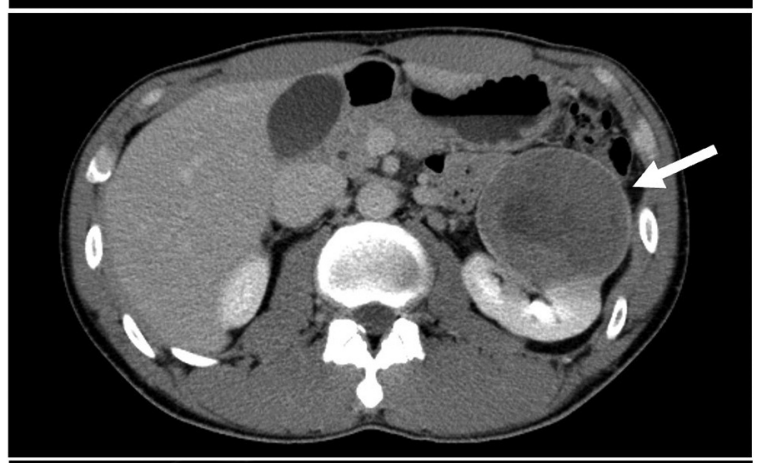

D

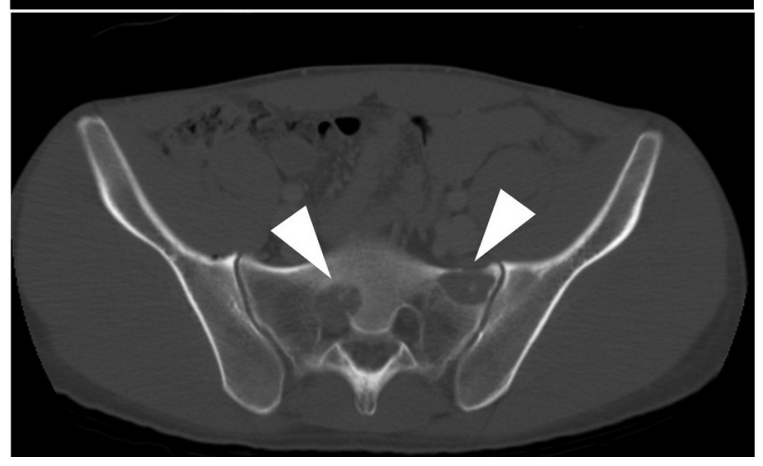

Figure 1. Pretreatment CT findings. (A-C) CT revealed a 72-mm tumor (white arrow) at the upper pole of the left kidney that was wellcircumscribed and slightly enhanced heterogeneously in the corticomedullary phase and excretory phase. (D) Multiple osteolytic changes were confirmed in bone (white arrowhead).

necrosis and spindle cells. The stroma had basophilic to eosinophilic mucin, aggregates of plasmacytes, and hyalinization. The left kidney biopsy specimen, which had been fixed in formalin, was stained with primary antibodies recognizing cytokeratin 7 (CK7; Leica Biosystems, Wetzlar, Germany), $\alpha$-Methylacyl-CoA racemase (AMACR; Leica Biosystems), cytokeratin AE1/AE3 (AE1/AE3; Agilent, Santa Clara, CA, USA), transcription factor EB (TFEB; Santa Cruz Biotechnology, Dallas, TX, USA) and transcription factor E3 (TFE3; Roche Diagnostics, Basel, Switzerland). CK7, AMACR and AE1/AE3 were revealed using Refine Detection Kit Mixed DAB Refine (Leica Biosystems) in BOND-III (Leica Biosystems). TFEB and TFE3 were revealed using Histofine Simple Stain MAX PO (Nichirei, Tokyo, Japan). An immunohistochemical analysis revealed that the tumor cells were diffusely positive for CK7, AMACR and AE1/AE3 and negative for TFEB and TFE3. The histology and immunohistochemical profile were consistent with MTSCC of the kidney (Figure 2 and Figure 3 ). The bone biopsy specimen showed massive coagulation necrosis, containing bland tubular structures with focal oncocytic changes, accompanied by spindle cells. These features were similar to those of the left renal malignant tumor (Figure 4). The patient was diagnosed with MTSCC of the kidney with bone metastases (cT2aNOM1) and an 'intermediate risk', according to the International Metastatic Renal Cell Carcinoma Database Consortium (IMDC) criteria, fulfilling the criteria of two prognostic factors: i) anemia and ii) $<1$ year since the diagnosis.

Combination therapy once every 3 weeks, through intravenous administration of nivolumab ( $240 \mathrm{mg} /$ body $)$ and ipilimumab $(1 \mathrm{mg} / \mathrm{kg})$ was provided as the first-line therapy. At the same time, $120 \mathrm{mg}$ of denosumab was subcutaneously injected every 4 weeks, and palliative radiotherapy was also performed for bone metastases to control the bone pain in the first cervical and second lumbar vertebrae. After 4 cycles of the combination of nivolumab plus ipilimumab, CT revealed that the non-enhanced area was increased in the left renal tumor, and sclerotic changes had appeared in the bone metastases. Nivolumab monotherapy (once every 2 weeks, $240 \mathrm{mg} /$ body) was subsequently continued. The patient developed immune-related adverse events (irAEs), such as diarrhea, after four courses of nivolumab (Grade 3). CT showed no thickening of the intestinal tract; however, colonoscopy showed a slightly edematous mucosa and poor vascular visibility, while a colon biopsy showed colonic mucosa with mild chronic inflammatory infiltration. The diarrhea improved immediately after prednisolone was started at $1 \mathrm{mg} / \mathrm{kg} / \mathrm{day}$ to control the AEs. Subsequently, nivolumab was restarted, and CT was used to evaluate the therapeutic effect after eight courses, revealing that the left renal tumor had shrunk slightly, and the non-enhanced area was even further increased, as were the osteosclerosis changes in the bone metastases (Figure 5). The patient underwent cytoreductive nephrectomy (laparoscopic radical nephrectomy) after nine courses of nivolumab. 

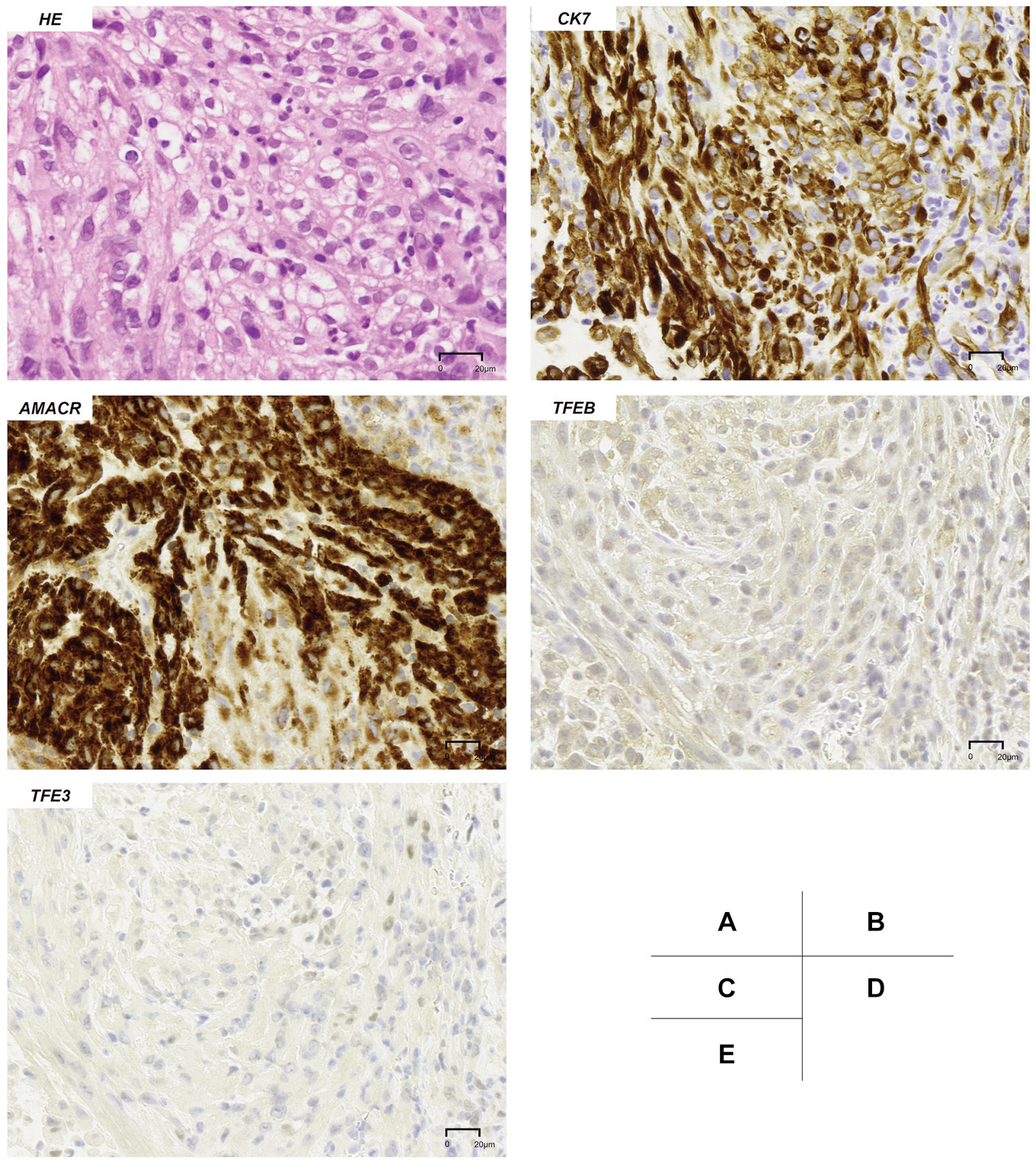

Figure 2. Immunostaining of the biopsy sample obtained from the left renal tumor for the diagnosis of mucinous tubular and spindle cell carcinoma (MTSCC). A CT-guided biopsy was performed on the part of the left renal tumor that was slightly enhanced heterogeneously in the corticomedullary phase. (A) Hematoxylin Eosin, (B) Cytokeratin 7 (CK7; brown), (C) a-Methylacyl-CoA racemase (AMACR; brown), (D) Transcription factor EB (TFEB; brown), (E) Transcription factor E3 (TFE3; brown). Scale bar=20 $\mu \mathrm{m}$.

Nivolumab treatment was resumed 2 weeks after surgery and a dose of $480 \mathrm{mg} /$ body together with denosumab (120 $\mathrm{mg}$ ) was administered every 4 weeks. At present, the observation period has been quite short, at 15 months, however, no progressive disease or irAEs has been observed so far. 

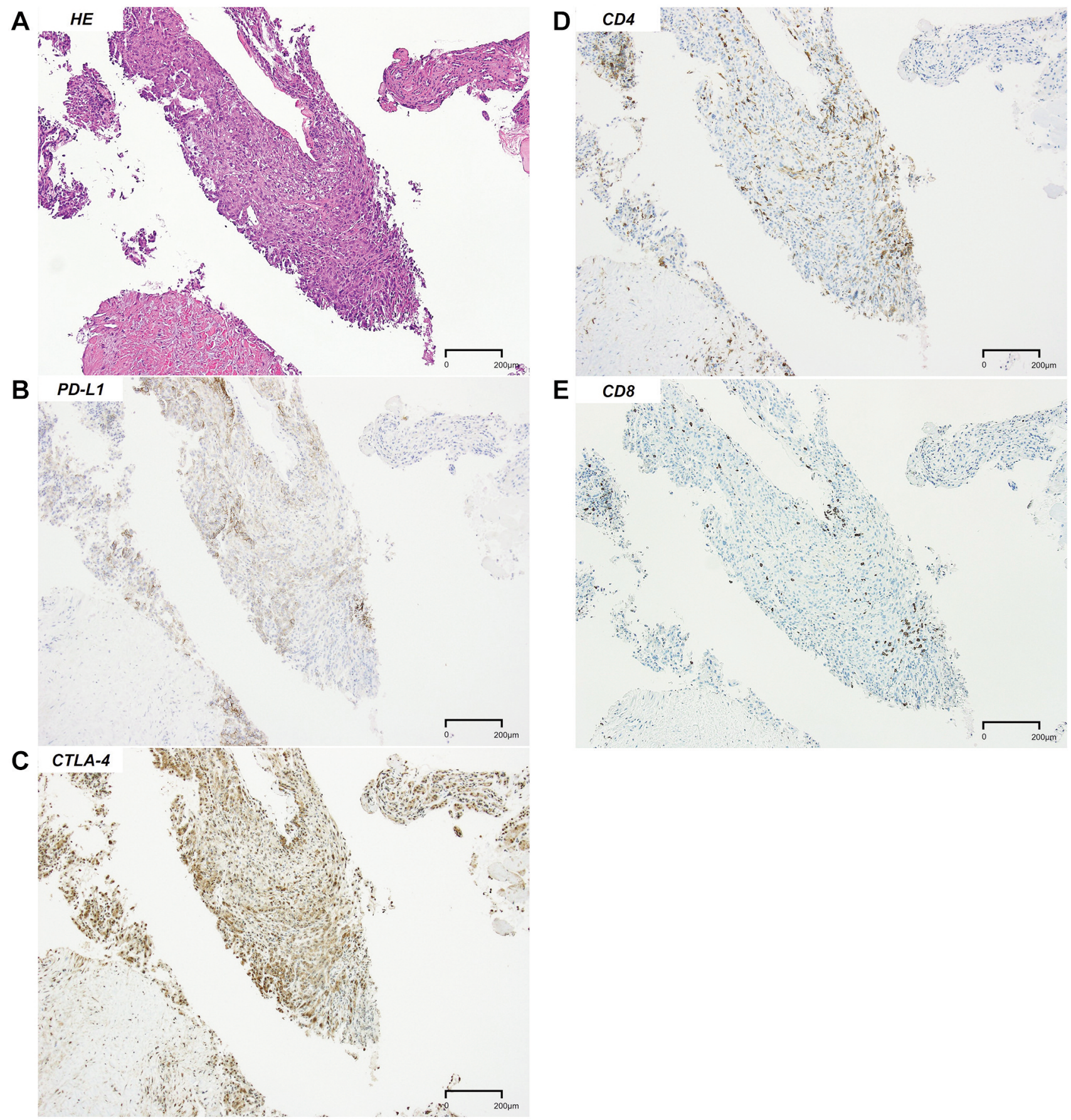

Figure 3. The biopsy of the left renal tumor. (A) Hematoxylin Eosin (HE), (B) programmed cell death ligand-1 (PD-L1) brown, (C) cytotoxic T lymphocyte-associated antigen-4 (CTLA-4; brown), (D) cluster of differentiation 4 (CD4; brown), (E) cluster of differentiation 8 (CD8; brown). Scale bar $=200 \mu \mathrm{m}$.

Pathological findings. Grossly, the tumor at the left kidney was mostly necrotic with hemorrhaging and white-toned solid parts (Figure 6). Histologically, the sections showed biphasic proliferation of a papillary or tubular pattern with atypical epithelial cells and clear or eosinophilic cytoplasm, as well as diffuse proliferation of atypical spindle-shaped cells, accompanied by inflammatory cell infiltration and necrosis. Nucleoli were prominent and easily visualized at 

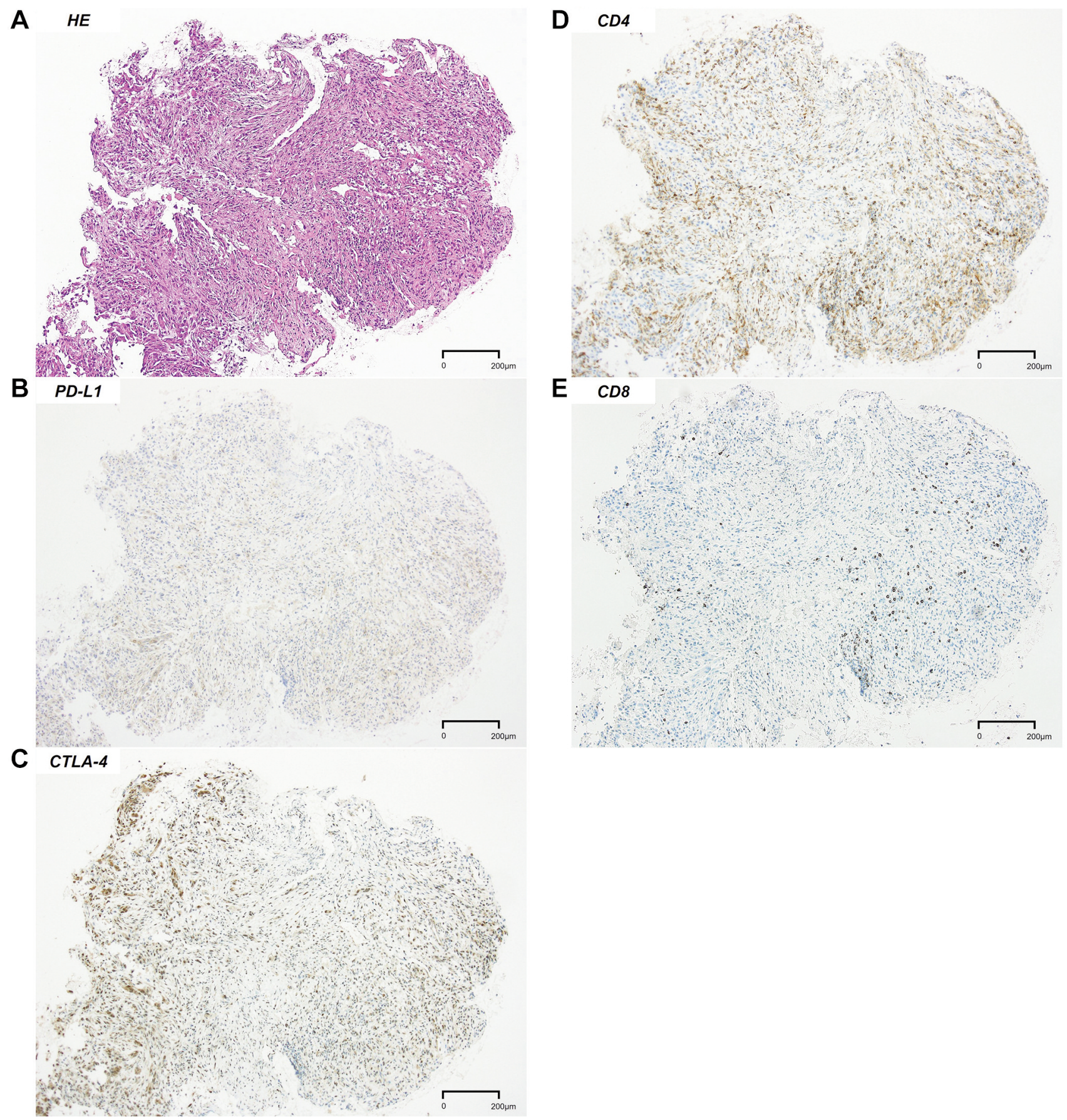

Figure 4. The biopsy of bone metastases. (A) Hematoxylin Eosin (HE), (B) programmed cell death ligand-1 (PD-L1; brown), (C) cytotoxic T lymphocyte-associated antigen-4 (CTLA-4; brown), (D) cluster of differentiation 4 (CD4; brown), (E) cluster of differentiation 8 (CD8; brown). Scale bar $=200 \mu \mathrm{m}$.

low-power magnification, showing a Grade 3 tumor, based on the scoring of the International Society of Urological Pathology. Mucin was observed in the interstitium of the tumor using Alcian blue staining (Muto pure chemicals,
Tokyo, Japan) (Figure 7). An immunohistochemical analysis via the same procedure as previously revealed that the tumor cells of the tubular/spindle components were positive for AE1/AE3 (+/+), Epithelial Membrane Antigens (EMA; Leica 
A

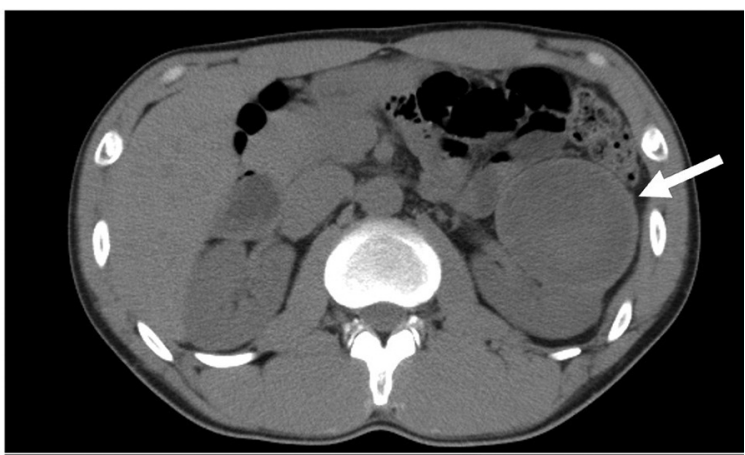

B

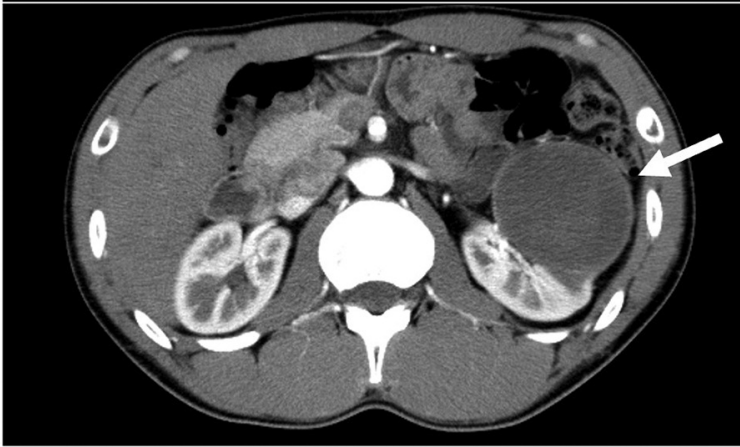

C

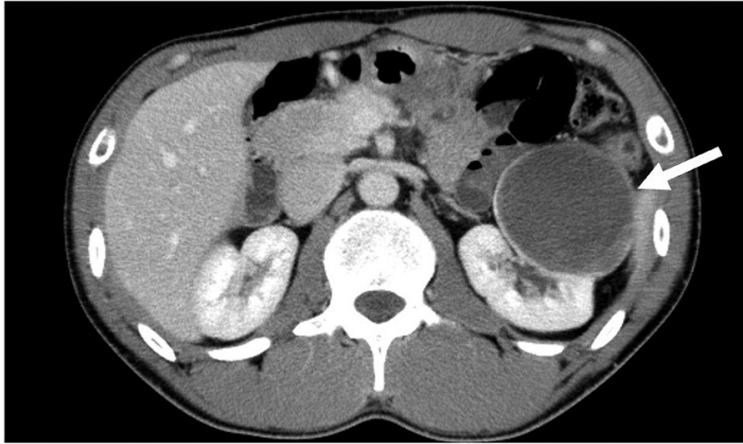

D

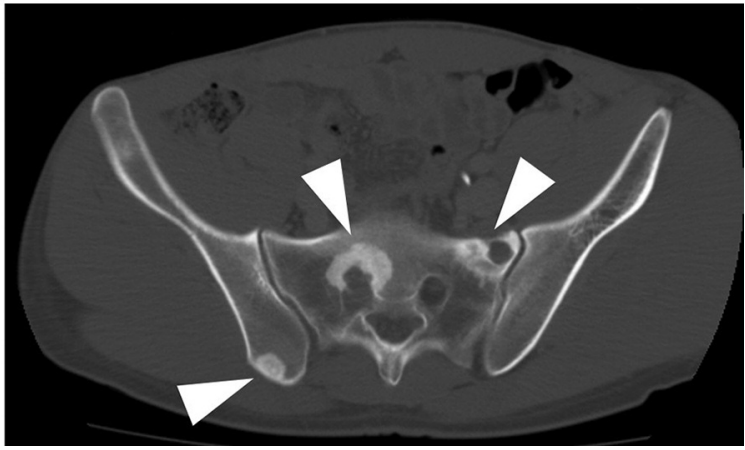

Figure 5. Computed Tomography (CT) after combination therapy of nivolumab plus ipilimumab and eight courses of nivolumab monotherapy. (A-C) CT revealed that the left renal tumor (white arrow) had shrunk slightly, and the non-enhanced area was increased.(D) The osteosclerotic changes in bone metastasis increased (white arrowhead).

Biosystems) $(+/+)$, vimentin (Agilent) $(+/+)$, Paired box protein-8 (PAX8; Biocare Medical, Pacheco, CA, USA) $(+/+)$, AMACR $(+/+)$ in the resected specimen after nivolumab plus ipilimumab. EMA, vimentin and PAX8 were revealed using Refine Detection Kit Mixed DAB Refine in BOND-III.

In addition, the biopsy of the pretreated renal tumor and bone metastasis and the resected specimen after nivolumab plus ipilimumab was evaluated by immunostaining of programmed cell death ligand 1 (PD-L1; Agilent), cytotoxic T lymphocyte-associated antigen-4 (CTLA-4; Santa Cruz Biotechnology), cluster of differentiation 4 (CD4; Roche Diagnostics), and cluster of differentiation 8 (CD8; Roche Diagnostics) via the same procedure as previously. PD-L1 was revealed using PD-L1 IHC 22C3 pharmDX (Dako, Santa Clara, CA, USA) in Autostainer Link 48 (Dako). CTLA4 was revealed using OptiView DAB IHC detection kit (Roche, Basel, Switzerland) in VENTANA BenchMark ULTRA (Roche). CD4 and CD8 were revealed using UltraView DAB IHC detection kit (Roche) in VENTANA BenchMark ULTRA. The PDL-1 expression was higher in the spindle components compared to the tubular ones, but CD4- and CD8-positve $\mathrm{T}$ cells showed greater infiltration in the tubular compared to the spindle components (Figure 8 and Figure 9). Furthermore, CD-4- and CD-8-positive $\mathrm{T}$ cells in both components of the resected specimen showed greater infiltration in the pretreatment biopsy of the renal tumor and bone metastases compared to the after-treatment biopsy (Figure 3 and Figure 4). There was no marked difference in the CTLA-4 expression between the spindle and tubular components in the resected specimen (Figure 8 and Figure 9).

Genomic findings. F-box and WD repeat domain containing 7 (FBXW7) is an F-box protein that belongs to the SKP1CUL1-F-box protein E3 ligase complex and is responsible for transferring the ubiquitin molecule to the substrate, which results in its recognition and subsequent degradation by the proteasomes (10). FBXW7 serves a key role as a suppressor gene in the cell cycle, proliferation, differentiation, apoptosis, tumor metastasis and drug resistance $(11,12)$ and has also been reported in renal cell carcinoma $(13,14)$. The nonsense variant S562* from a Serine mutation in the $F B X W 7$ gene was reported using next-generation sequencing with FoundationOne ${ }^{\circledR} \mathrm{CDx}$ (Foundation Medicine, Inc.). The tumor mutation burden was 2.52 mutations per megabase, and microsatellite instability was absent.

\section{Discussion}

MTSCC was originally reported as a rare histological type of RCC with a low malignant potential $(15,16)$. Patients with MTSCC of the kidney treated with surgical resection tend to generally have favorable outcomes. However, fatal cases of MTSCC with distant metastases have been reported $(3,17-21)$. No therapeutic strategy has yet been established for metastatic MTSCC, with the efficacy of targeted agents 

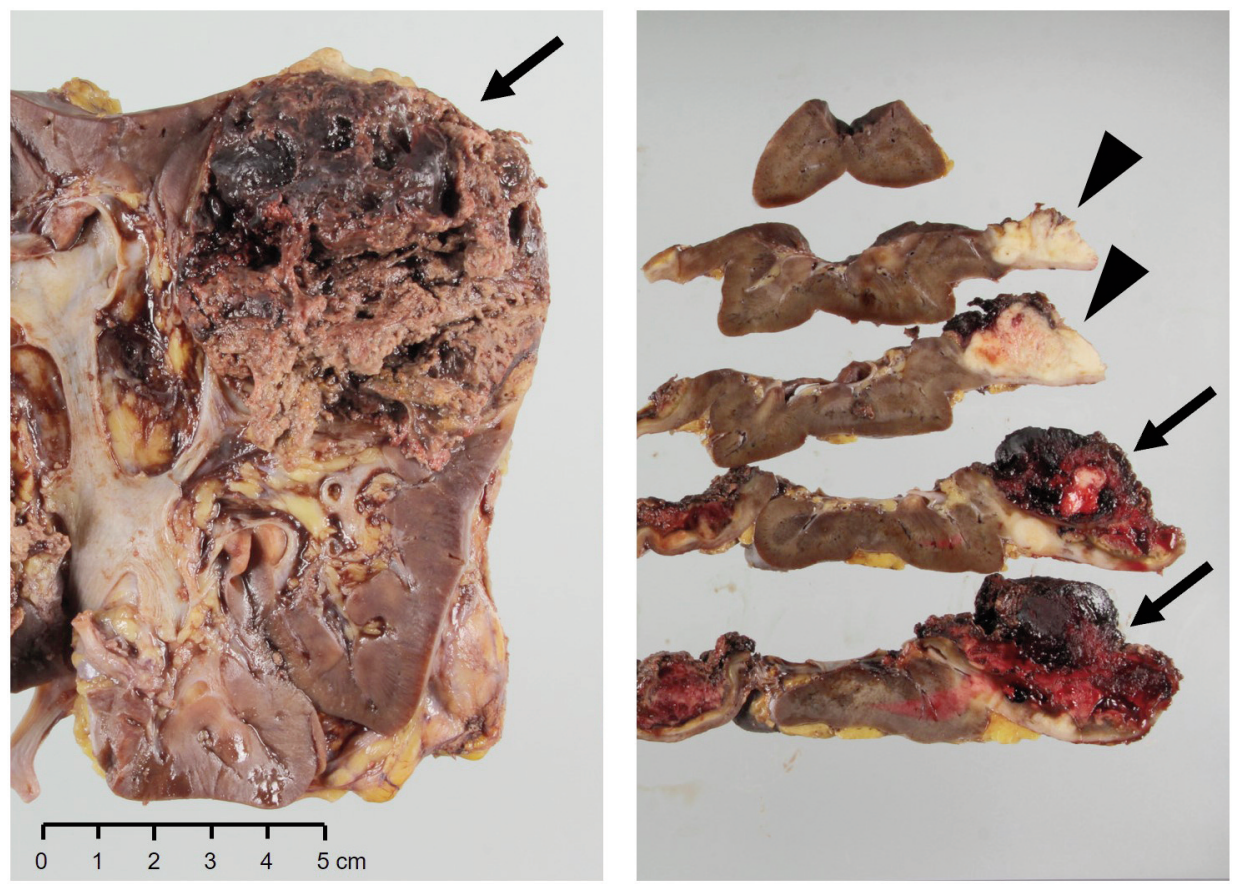

Figure 6. Macroscopic findings. The tumor at the upper pole of left kidney was mostly necrotic with hemorrhaging (black arrow) and white-toned solid parts (black arrowhead).

and monotherapy of immune checkpoint inhibitors reported in only a few case reports (3-8). Only one case report regarding the combination of nivolumab plus ipilimumab for metastatic MTSCC after cytoreductive nephrectomy has recently been reported, showing some efficacy (9).

Ipilimumab is a humanized monoclonal IgG1 anticytotoxic T-lymphocyte antigen-4 antibody that, in combination with nivolumab, a fully human IgG4 PD-1 immune checkpoint inhibitor antibody, was recently approved by the Food and Drug Administration as a first-line treatment of IMDC intermediate- and poor-risk metastatic clear cell RCC, after the Checkmate 214 trial showed a significantly improved progression-free survival and overall survival (OS) with combination therapy (22). However, nonclear cell RCC histology specimens were excluded from the trial, so the activity of nivolumab plus ipilimumab for nonclear cell RCC remains unknown.

According to the National Comprehensive Cancer Network guidelines, sunitinib, a multi-targeted tyrosine kinase inhibitor, is a preferred systemic regimen for nonclear cell histology (23). A meta-analysis of three studies concluded that sunitinib results in favorable outcomes compared to everolimus, a mammalian target of rapamycin inhibitor, for first-line therapy (24). However, combination therapy of nivolumab plus ipilimumab was chosen in the present case because there was a possibility that combination immunotherapy might be more effective for bone metastases and show a more durable response compared to targeted agents, such as sunitinib.

A retrospective analysis of the combination of nivolumab plus ipilimumab for non-clear cell RCC has already been reported in a small cohort; however, that study did not include MSTCC of the kidney (25). To our knowledge, the present case is the first one to be treated with combination therapy of nivolumab plus ipilimumab for MTSCC of the kidney with bone metastases. In addition, the present patient underwent nephrectomy, and the immunological therapeutic effect in the resected specimen was also evaluated.

Impressively, two different components-tubular and spindle-were confirmed in the same preparation of the excised specimen and showed a differing expression on immunohistochemical staining. Specifically, PD-L1 expression was higher in the spindle components compared to the tubular components. The expression of the immune checkpoint PD-L1 is reportedly higher at the surface of sarcomatoid RCC cells compared to non-sarcomatoid RCC cells, regardless of the parent histology or non-sarcomatoid RCC tumor grade $(26,27)$.

Regarding sarcomatoid RCC, while in a consensus conference the definition of sarcomatoid RCC was discussed, no consensus was ultimately obtained (28). The largest percentage $(41 \%)$ of participants felt that a tumor is sarcomatoid if it consists of atypical spindle cells and resembles any form of sarcoma. However, another group 


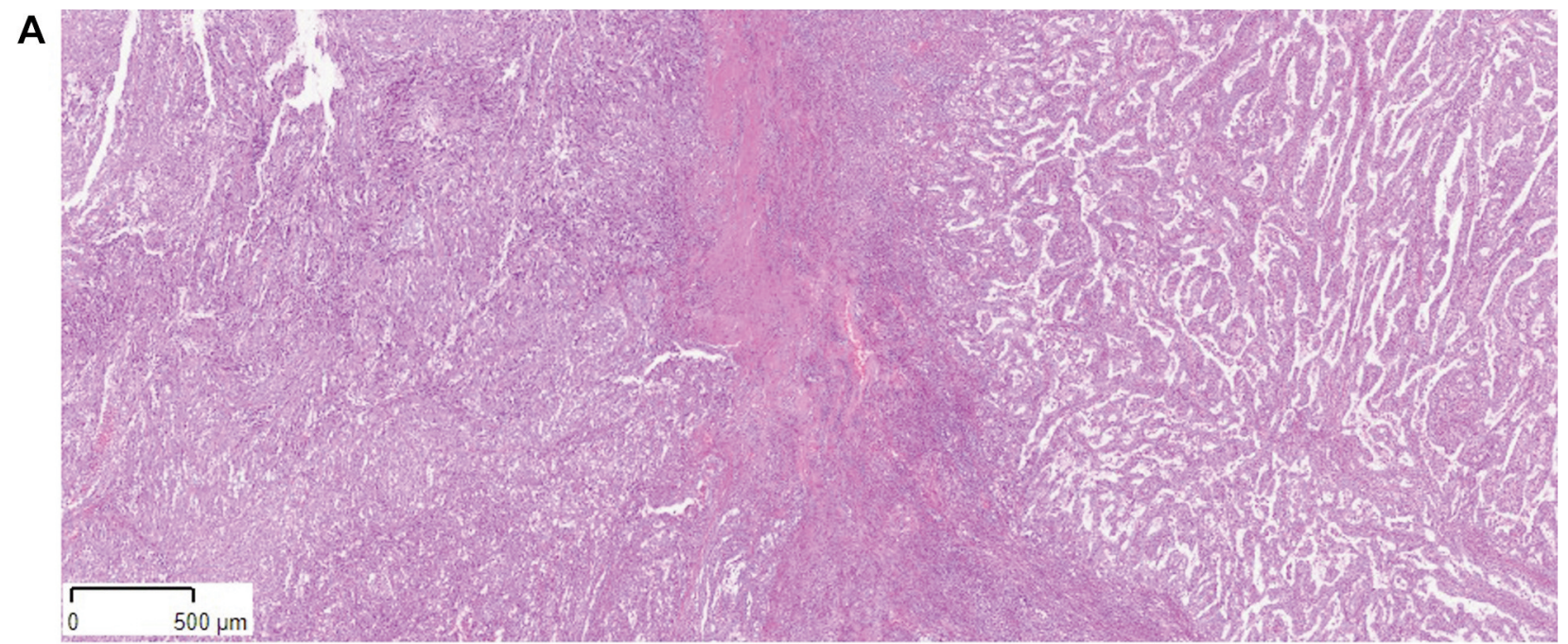

B

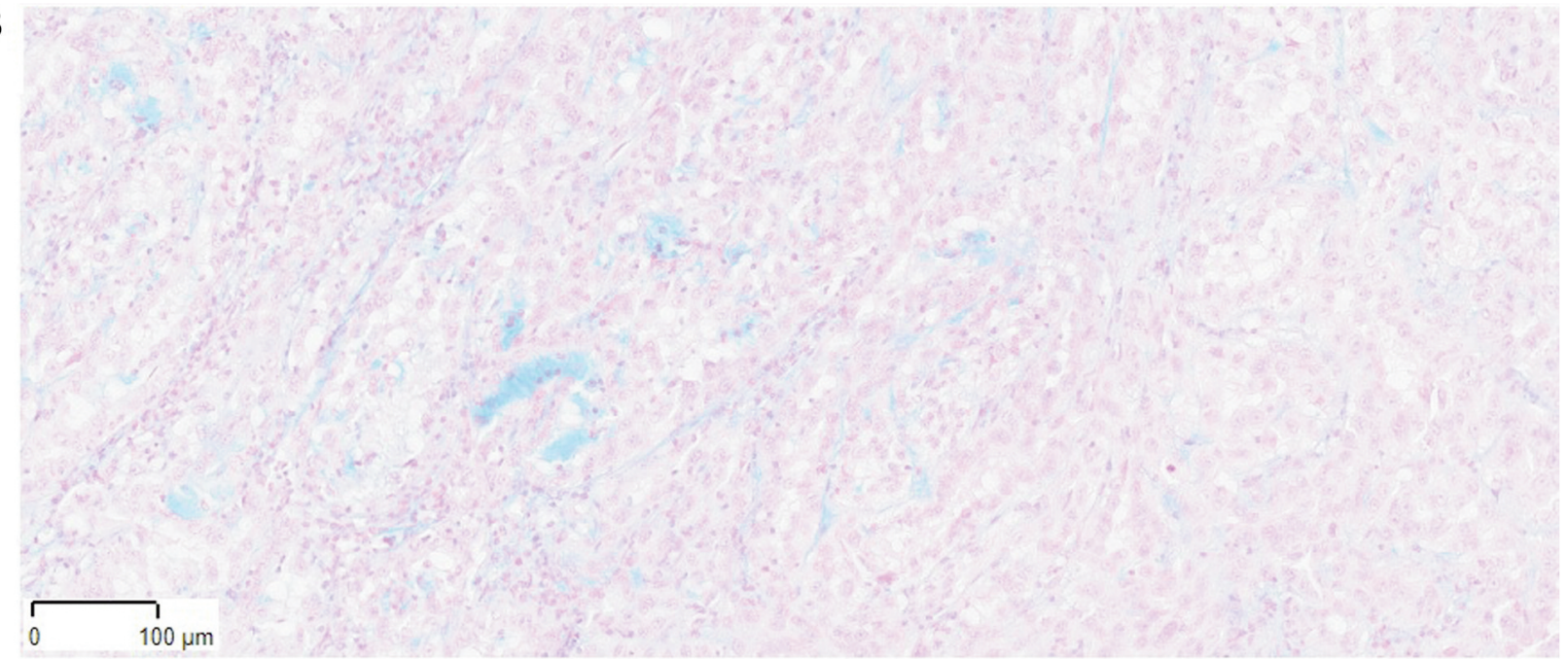

Figure 7. Excised specimen. (A) Hematoxylin eosin, tubular components on the right side and spindle components on the left side. Scale bar=500 $\mu \mathrm{m}$. (B) Alcian blue staining. Scale bar=100 $\mu \mathrm{m}$.

(22\%) considered a tumor sarcomatoid if it has a spindle cell pattern. In the present case, the tumor did not show any sarcomatoid changes but did have spindle components with grade 3 nuclear grading. Therefore, the spindle components of the present case may have similar characteristics to sarcomatoid RCC. CD4 and CD8 staining revealed a difference between the tubular and spindle components, and both CD4- and CD8-positve $\mathrm{T}$ cells showed greater infiltration in the tubular components than in the spindle components in the resected specimen.

Transforming growth factor receptor- $\beta$ (TGF- $\beta$ ) signaling in the tumor microenvironment has been associated with a poor prognosis (29), and transcriptional analyses have suggested that this and other pathways are enriched in sarcomatoid RCC (30). As a pleiotropic cytokine, TGF- $\beta$ maintains immune homeostasis through the regulation of essentially every cell type of the innate and adaptive immune system. Specifically, TGF- $\beta$ suppresses the proliferation, differentiation, and effector functions of multiple immune cell types, especially $\mathrm{T}$ lymphocytes, and induces the generation of immunosuppressive cells or phenotypes (31, 32). TGF- $\beta$ may, thus, be involved with the weak infiltration of CD4- and CD8-positive T cells in the spindle components compared to the tubular ones.

A mutation in the $F B X W 7$ gene was reported in this case using next-generation sequencing with FoundationOne ${ }^{\circledR} \mathrm{CDx}$. Analysis of pathological specimens from renal cancer patients has shown that the prognosis of patients with low expression of $F B X W 7$ is poorer compared to that of patients with high expression (13). The Ser562 mutation reported in 

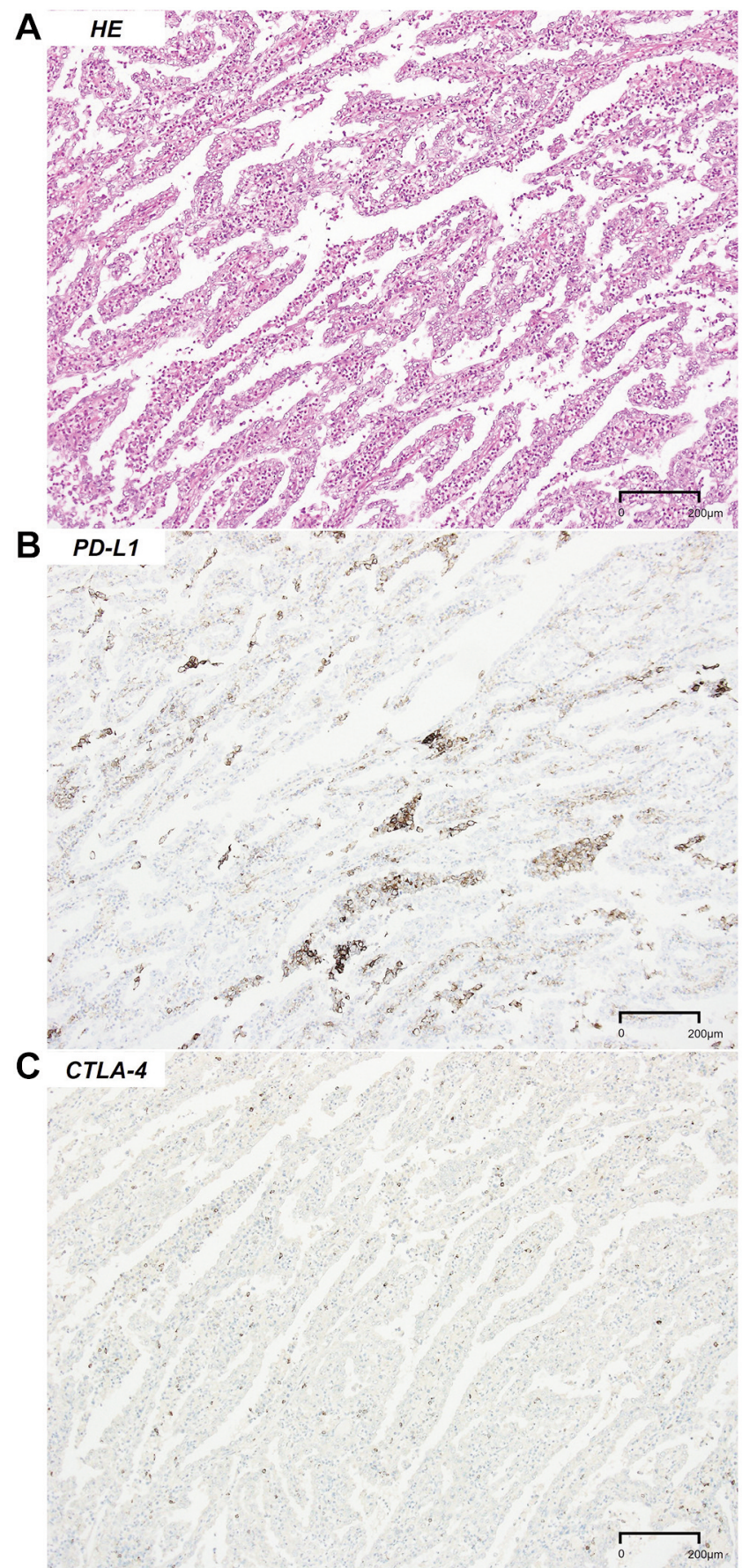

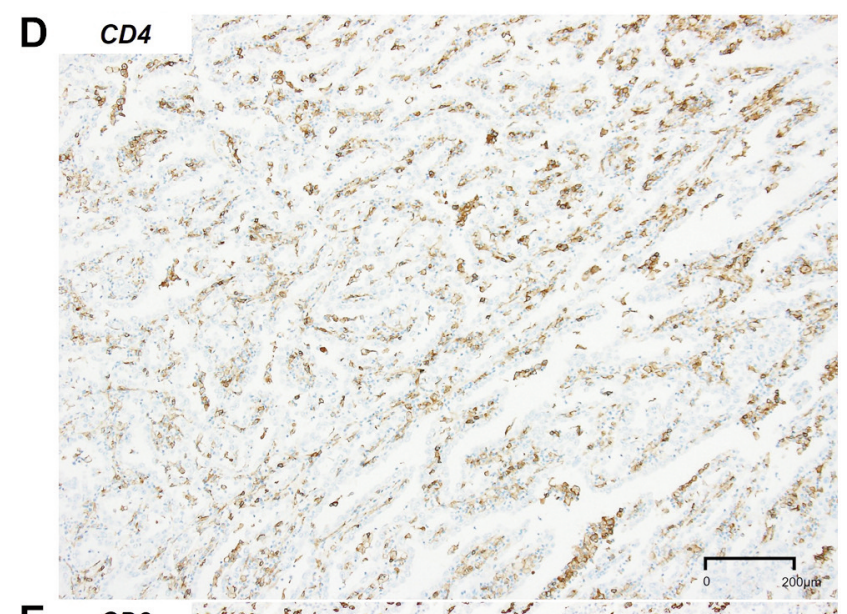

E

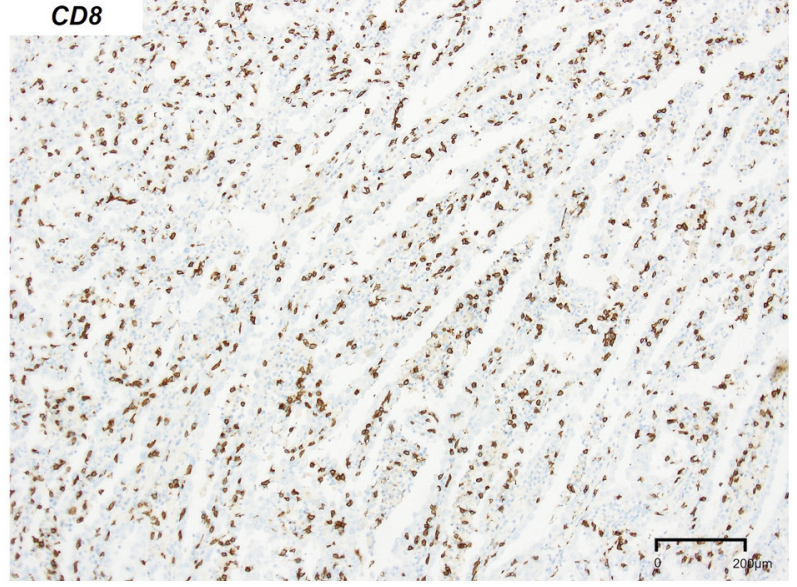

Figure 8. Tubular components. (A) Hematoxylin Eosin (HE), (B) programmed cell death ligand-1 (PD-L1; brown), (C) cytotoxic T lymphocyteassociated antigen-4 (CTLA-4; brown); (D) cluster of differentiation 4 (CD4; brown), (E) cluster of differentiation 8 (CD8; brown). Scale bar $=200 \mu \mathrm{m}$.

this study is located in the WD40 domain, which is important for the function of the $F B X W 7$ protein (33). Since it is a nonsense mutation, this mutation may impair the function of $F B X W 7$ as a tumor suppressor gene and, thus, have a negative impact on prognosis. In MTSCC, the mutation of $F B X W 7$ was recently detected in 1 out of 10 cases of locally advanced/metastatic-MTSCC (34). Independent validation in a large cohort using wholeexosome studies should be performed to clarify the implications of $F B X W 7$ in MTSCC; however, given the 

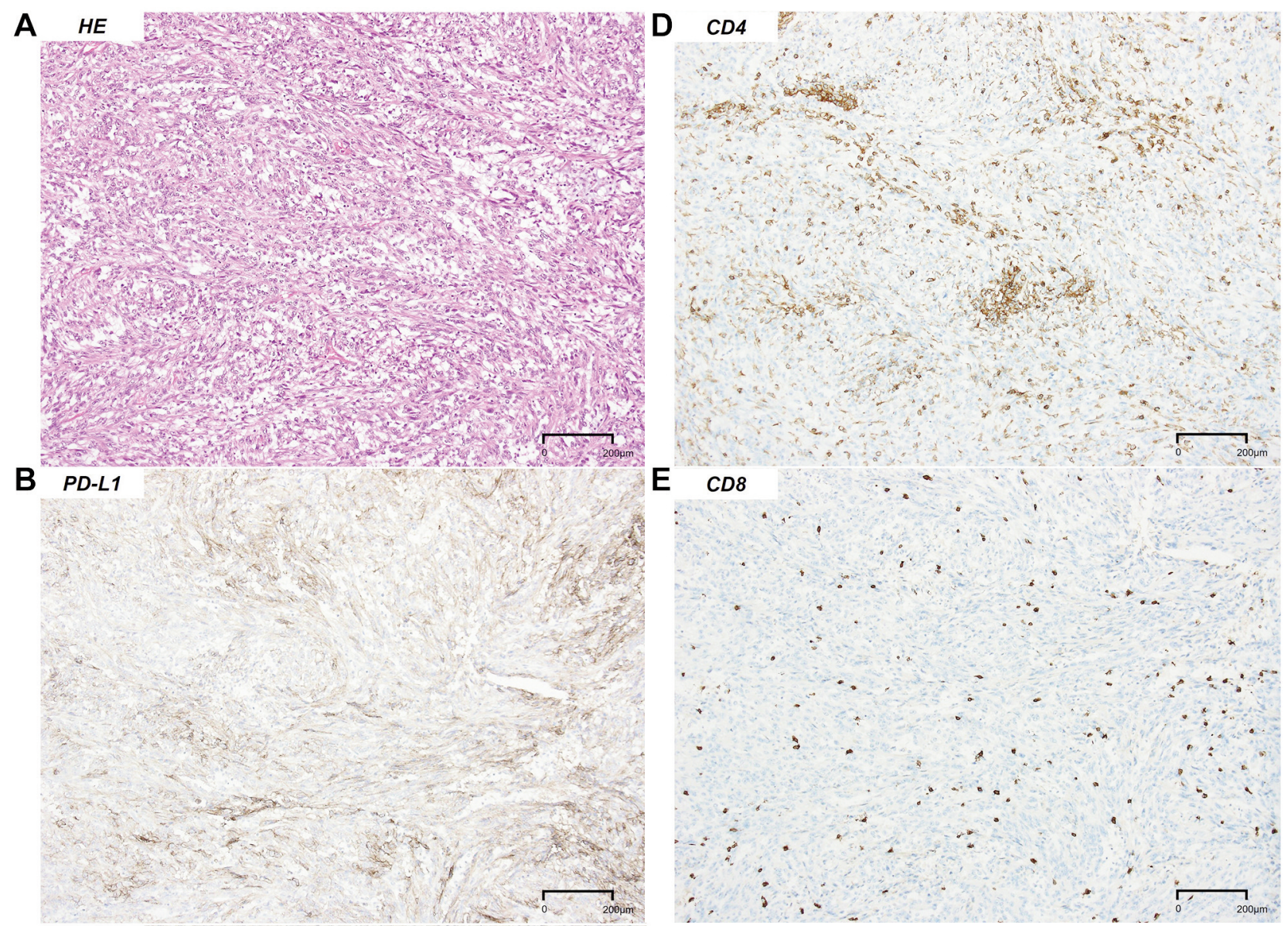

\section{CTLA-4}

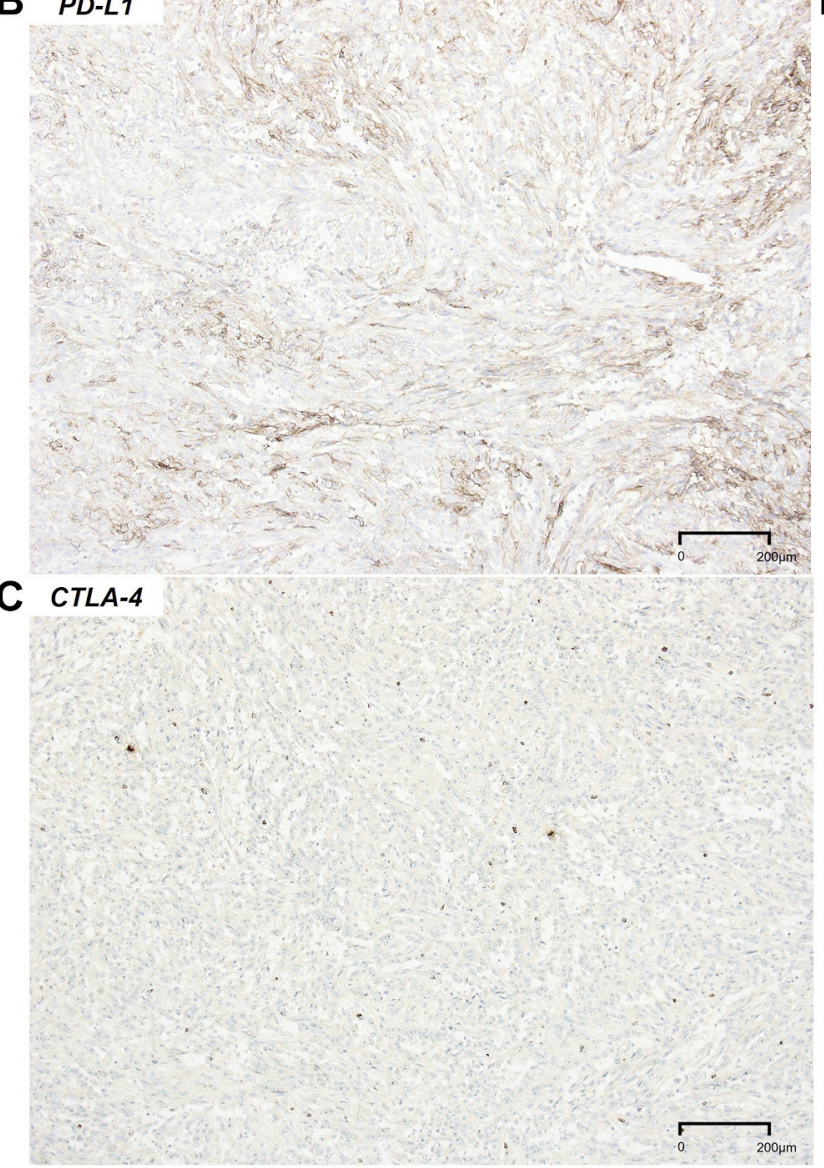

Figure 9. Spindle components. (A) Hematoxylin Eosin (HE), (B) programmed cell death ligand-1 (PD-L1) brown, (C) cytotoxic T lymphocyteassociated antigen-4 (CTLA-4; brown), (D) cluster of differentiation 4 (CD4; brown), (E) cluster of differentiation 8 (CD8; brown). Scale bar $=200 \mu \mathrm{m}$.

rarity of these cases, this may be very difficult from a practical point of view.

In conclusion, here we report the first case of cytoreductive nephrectomy after combination of nivolumab plus ipilimumab therapy for MTSCC of the kidney with bone metastases. MTSCC of the kidney is a rare subtype of RCC, and there is currently no standard therapeutic care established for it. Interestingly, the present case suggests that combination immunotherapy may be an effective treatment option for metastatic MTSCC of the kidney. More studies 
with a larger number of patients with this rare disease are needed to confirm our novel findings.

\section{Conflicts of Interest}

The Authors declare that they have no conflicts of interest for this study.

\section{Authors' Contributions}

NF, TN, AM, YS, MM and MN planned the case study, collected and analysed the clinical date. NF, KT, TN and MN preformed immunohistochemical examination and interpreted the pathological findings. NF, TN and MN wrote the manuscript. All Authors read and approved the final manuscript.

\section{References}

1 Eble JN, Sauter G, Epstein JI and Sesterhenn IA: The World Health Organization Classification of Tumours of the Urinary System and Male Genital System. Lyon, France, IARC Press, 2004.

2 Sadimin ET, Chen YB, Wang L, Argani P and Epstein JI: Chromosomal abnormalities of high-grade mucinous tubular and spindle cell carcinoma of the kidney. Histopathology 71(5): 719724, 2017. PMID: 28656700. DOI: 10.1111/his.13298

3 Ged Y, Chen YB, Knezevic A, Donoghue MTA, Carlo MI, Lee $\mathrm{CH}$, Feldman DR, Patil S, Hakimi AA, Russo P, Voss MH and Motzer RJ: Mucinous tubular and spindle-cell carcinoma of the kidney: Clinical features, genomic profiles, and treatment outcomes. Clin Genitourin Cancer 17(4): 268-274.e1, 2019. PMID: 31151928. DOI: 10.1016/j.clgc.2019.04.006

4 Isono M, Seguchi K, Yamanaka M, Miyai K, Okubo K and Ito $\mathrm{K}$ : Rapid progression of mucinous tubular and spindle cell carcinoma of the kidney without sarcomatoid changes: A case report. Urol Case Rep 31: 101162, 2020. PMID: 32300530. DOI: 10.1016/j.eucr.2020.101162

5 Larkin J, Fisher R, Pickering L, Thway K, Livni N, Fisher C and Gore M: Metastatic mucinous tubular and spindle cell carcinoma of the kidney responding to sunitinib. J Clin Oncol 28(28): e539e540, 2010. PMID: 20679595. DOI: 10.1200/JCO.2010.30.1457

6 Thway K, du Parcq J, Larkin JM, Fisher C and Livni N: Metastatic renal mucinous tubular and spindle cell carcinoma. Atypical behavior of a rare, morphologically bland tumor. Ann Diagn Pathol 16(5): 407-410, 2012. PMID: 21684183. DOI: 10.1016/j.anndiagpath.2011.04.001

7 Chahoud J, Msaouel P, Campbell MT, Bathala T, Xiao L, Gao J, Zurita AJ, Shah AY, Jonasch E, Sharma P and Tannir NM: Nivolumab for the treatment of patients with metastatic nonclear cell renal cell carcinoma (nccRCC): A single-institutional experience and literature meta-analysis. Oncologist 25(3): 252258, 2020. PMID: 32162795. DOI: 10.1634/theoncologist.20190372

8 Koshkin VS, Barata PC, Zhang T, George DJ, Atkins MB, Kelly WJ, Vogelzang NJ, Pal SK, Hsu J, Appleman LJ, Ornstein MC, Gilligan T, Grivas P, Garcia JA and Rini BI: Clinical activity of nivolumab in patients with non-clear cell renal cell carcinoma. J Immunother Cancer 6(1): 9, 2018. PMID: 29378660. DOI: 10.1186/s40425-018-0319-9
9 Fuchizawa H, Kijima T, Takada-Owada A, Nagashima Y, Okazaki A, Yokoyama M, Nishihara D, Ishida K and Kamai T: Metastatic mucinous tubular and spindle cell carcinoma of the kidney responding to nivolumab plus ipilimumab. IJU Case Rep 4(5): 333-337, 2021. PMID: 34497997. DOI: 10.1002/iju5. 12342

10 Wang Z, Inuzuka H, Fukushima H, Wan L, Gao D, Shaik S, Sarkar FH and Wei W: Emerging roles of the FBW7 tumour suppressor in stem cell differentiation. EMBO Rep 13(1): 36-43, 2011. PMID: 22157894. DOI: 10.1038/embor.2011.231

11 Welcker M and Clurman BE: FBW7 ubiquitin ligase: a tumour suppressor at the crossroads of cell division, growth and differentiation. Nat Rev Cancer 8(2): 83-93, 2008. PMID: 18094723. DOI: $10.1038 / \mathrm{nrc} 2290$

12 Wang Z, Inuzuka H, Zhong J, Wan L, Fukushima H, Sarkar FH and Wei W: Tumor suppressor functions of FBW7 in cancer development and progression. FEBS Lett 586(10): 1409-1418, 2012. PMID: 22673505. DOI: 10.1016/j.febslet.2012.03.017

13 He H, Dai J, Xu Z, He W, Wang X, Zhu Y and Wang H: Fbxw7 regulates renal cell carcinoma migration and invasion via suppression of the epithelial-mesenchymal transition. Oncol Lett 15(3): 3694-3702, 2018. PMID: 29456733. DOI: 10.3892/ol.2018.7744

14 Smith PS, Whitworth J, West H, Cook J, Gardiner C, Lim DHK, Morrison PJ, Hislop RG, Murray E, NIHR Rare Disease BioResource., Tischkowitz M, Warren AY, Woodward ER and Maher ER: Characterization of renal cell carcinoma-associated constitutional chromosome abnormalities by genome sequencing. Genes Chromosomes Cancer 59(6): 333-347, 2020. PMID: 31943436 . DOI: $10.1002 / \mathrm{gcc} .22833$

15 Lopez-Beltran A, Scarpelli M, Montironi R and Kirkali Z: 2004 WHO classification of the renal tumors of the adults. Eur Urol 49(5): 798-805, 2006. PMID: 16442207. DOI: 10.1016/ j.eururo.2005.11.035

16 Moch H, Humphrey PA, Ulbright TM and Reuter VE: WHO classification of tumors of the Urinary System and Male Genital Organs, $4^{\text {th }}$ edn. Lyon, France, IARC Press, 2016.

17 Dhillon J, Amin MB, Selbs E, Turi GK, Paner GP and Reuter VE: Mucinous tubular and spindle cell carcinoma of the kidney with sarcomatoid change. Am J Surg Pathol 33(1): 44-49, 2009. PMID: 18941398. DOI: 10.1097/PAS.0b013e3181829ed5

18 Bulimbasic S, Ljubanovic D, Sima R, Michal M, Hes O, Kuroda $\mathrm{N}$ and Persec Z: Aggressive high-grade mucinous tubular and spindle cell carcinoma. Hum Pathol 40(6): 906-907, 2009. PMID: 19442792. DOI: 10.1016/j.humpath.2009.03.004

19 Sokolakis I, Kalogirou C, Frey L, Oelschläger M, Krebs M, Riedmiller H, Kübler H and Vergho D: Mucin-poor mucinous tubular and spindle cell carcinoma of the kidney presented with multiple metastases two years after nephrectomy: an atypical behaviour of a rare, indolent tumour. Case Rep Urol 2017: 6597592, 2017. PMID: 29348963. DOI: 10.1155/2017/6597592

20 Sakatani T, Okumura Y, Kuroda N, Magaribuchi T, Nakano Y, Shirahase T, Watanabe J, Taki Y, Okigaki M, Ikehara S and Adachi Y: Mucinous tubular and spindle cell carcinoma with a high nuclear grade and micropapillary pattern: A case report. Mol Clin Oncol 7(6): 976-980, 2017. PMID: 29285359. DOI: $10.3892 /$ mco. 2017.1430

21 Uchida S, Suzuki K, Uno M, Nozaki F, Li CP, Abe E, Yamauchi T, Horiuchi S, Kamo M, Hattori K and Nagashima Y: Mucinpoor and aggressive mucinous tubular and spindle cell 
carcinoma of the kidney: Two case reports. Mol Clin Oncol 7(5): 777-782, 2017. PMID: 29075488. DOI: 10.3892/mco.2017.1400 22 Motzer RJ, Tannir NM, McDermott DF, Arén Frontera O, Melichar B, Choueiri TK, Plimack ER, Barthélémy P, Porta C, George S, Powles T, Donskov F, Neiman V, Kollmannsberger CK, Salman P, Gurney H, Hawkins R, Ravaud A, Grimm MO, Bracarda S, Barrios CH, Tomita Y, Castellano D, Rini BI, Chen AC, Mekan S, McHenry MB, Wind-Rotolo M, Doan J, Sharma P, Hammers HJ, Escudier B and CheckMate 214 Investigators: Nivolumab plus ipilimumab versus sunitinib in advanced renalcell carcinoma. N Engl J Med 378(14): 1277-1290, 2018. PMID: 29562145. DOI: 10.1056/NEJMoa1712126

23 National Comprehensive Cancer Network: Guidelines on kidney cancer. Available at: https://www.nccn.org/professionals/ physician_gls/pdf/kidney.pdf [Last accessed on February 3, 2021]

24 Vera-Badillo FE, Templeton AJ, Duran I, Ocana A, de Gouveia P, Aneja P, Knox JJ, Tannock IF, Escudier B and Amir E: Systemic therapy for non-clear cell renal cell carcinomas: a systematic review and meta-analysis. Eur Urol 67(4): 740-749, 2015. PMID: 24882670. DOI: 10.1016/j.eururo.2014.05.010

25 Gupta R, Ornstein MC, Li H, Allman KD, Wood LS, Gilligan T, Garcia JA, Merveldt DV, Hammers HJ and Rini BI: Clinical activity of ipilimumab plus nivolumab in patients with metastatic non-clear cell renal cell carcinoma. Clin Genitourin Cancer 18(6): 429-435, 2020. PMID: 32800717. DOI: 10.1016/ j.clgc.2019.11.012

26 Kawakami F, Sircar K, Rodriguez-Canales J, Fellman BM, Urbauer DL, Tamboli P, Tannir NM, Jonasch E, Wistuba II, Wood CG and Karam JA: Programmed cell death ligand 1 and tumor-infiltrating lymphocyte status in patients with renal cell carcinoma and sarcomatoid dedifferentiation. Cancer 123(24): 4823-4831, 2017. PMID: 28832979. DOI: 10.1002/cncr.30937

27 Joseph RW, Millis SZ, Carballido EM, Bryant D, Gatalica Z, Reddy S, Bryce AH, Vogelzang NJ, Stanton ML, Castle EP and Ho TH: PD-1 and PD-L1 expression in renal cell carcinoma with sarcomatoid differentiation. Cancer Immunol Res 3(12): 13031307, 2015. PMID: 26307625. DOI: 10.1158/2326-6066.CIR15-0150

28 Delahunt B, Cheville JC, Martignoni G, Humphrey PA, MagiGalluzzi C, McKenney J, Egevad L, Algaba F, Moch H, Grignon DJ, Montironi R, Srigley JR and Members of the ISUP Renal Tumor Panel: The International Society of Urological Pathology (ISUP) grading system for renal cell carcinoma and other prognostic parameters. Am J Surg Pathol 37(10): 1490-1504, 2013. PMID: 24025520. DOI: 10.1097/PAS.0b013e318299f0fb
29 Calon A, Lonardo E, Berenguer-Llergo A, Espinet E, HernandoMomblona X, Iglesias M, Sevillano M, Palomo-Ponce S, Tauriello DV, Byrom D, Cortina C, Morral C, Barceló C, Tosi S, Riera A, Attolini CS, Rossell D, Sancho E and Batlle E: Stromal gene expression defines poor-prognosis subtypes in colorectal cancer. Nat Genet 47(4): 320-329, 2015. PMID: 25706628. DOI: $10.1038 /$ ng.3225

30 Wang Z, Kim TB, Peng B, Karam J, Creighton C, Joon A, Kawakami F, Trevisan P, Jonasch E, Chow CW, Canales JR, Tamboli P, Tannir N, Wood C, Monzon F, Baggerly K, VarellaGarcia M, Czerniak B, Wistuba I, Mills G, Shaw K, Chen K and Sircar K: Sarcomatoid renal cell carcinoma has a distinct molecular pathogenesis, driver mutation profile, and transcriptional landscape. Clin Cancer Res 23(21): 6686-6696, 2017. PMID: 28710314. DOI: 10.1158/1078-0432.CCR-17-1057

31 Akhurst RJ and Hata A: Targeting the TGF $\beta$ signalling pathway in disease. Nat Rev Drug Discov 11(10): 790-811, 2012. PMID: 23000686. DOI: $10.1038 / \mathrm{nrd} 3810$

32 Flavell RA, Sanjabi S, Wrzesinski SH and Licona-Limón P: The polarization of immune cells in the tumour environment by TGFbeta. Nat Rev Immunol 10(8): 554-567, 2010. PMID: 20616810. DOI: $10.1038 /$ nri2808

33 Lee CJ, An HJ, Kim SM, Yoo SM, Park J, Lee GE, Kim WY, Kim DJ, Kang HC, Lee JY, Lee HS, Cho SJ and Cho YY: FBXW7-mediated stability regulation of signal transducer and activator of transcription 2 in melanoma formation. Proc Natl Acad Sci U.S.A. 117(1): 584-594, 2020. PMID: 31843895. DOI: 10.1073/pnas.1909879116

34 Yang C, Cimera RS, Aryeequaye R, Jayakumaran G, Sarungbam J, Al-Ahmadie HA, Gopalan A, Sirintrapun SJ, Fine SW, Tickoo SK, Epstein JI, Reuter VE, Zhang Y and Chen YB: Adverse histology, homozygous loss of CDKN2A/B, and complex genomic alterations in locally advanced/metastatic renal mucinous tubular and spindle cell carcinoma. Mod Pathol 34(2): 445-456, 2021. PMID: 32879414. DOI: 10.1038/s41379-02000667-9
Received August 4, 2021

Revised November 2, 2021

Accepted November 4, 2021 